\title{
Speech Production: Motor Programming of Phonetic Features
}

\author{
David E. Meyer and Peter C. Gordon \\ University of Michigan
}

\begin{abstract}
Three experiments are reported on the role of phonetic features in motor programs for speech production. Each experiment involved a type of response-priming procedure. The procedure required subjects to prepare a specified primary vocal response that contained one or two vowel-consonant syllables (e.g., "up," "ub." "ut," and "ud"). After the preparation interval, the subjects either produced the primary response upon command or else switched to produce another specified secondary response instead. Response latency and accuracy were measured as a function of the relationship between the phonetic features of the primary and secondary responses. Longer latencies and more errors occurred when the secondary response had place-of-articulation or voicing features identical to those of the primary response. The results may be interpreted in terms of an interactive-activation model. It appears that phonetic features play a significant role during the compilation of articulatory motor programs, and that preparation to produce an utterance inhibits the programming of other utterances with similar features. This outcome complements and extends conclusions derived from analyzing naturalistic slips of the tongue and coarticuJation phenomena. The interactive-activation model of speech production provides a link with theoretical accounts of speech perception. word recognition, and manual movement. 1985 Academic Press, inc
\end{abstract}

Current theories of human speech production hypothesize that production processes work with information coded at various levels of abstraction (Garrett, 1975, 1980; Kent, 1976a; MacNeilage \& Ladefoged. 1976). The information is thought to be organized hierarchically, ranging from relatively large structures to intermediate

This research was supported by grants to D. E. Meyer from the National Science Foundation (BNS 82-06809) and the Horace Rackham School of Graduate Studies at the University of Michigan. P. C. Gordon participated under the sponsorship of a training grant (MH16892-01) from the National Institute of Mental Health. The authors thank R. Abrams. L. Barry. P. Benson, B. Holcomb, C. Huff, D. Hut tenlocher, R. Keifer, L. Roshwalb, E. Sammons, and J. Sullivan for helpful advice and technical assisiance. Comments and suggestions by $M$. Just. D. G. MacKay, and D. Rosenbaum are also gratefully acknowledged. Requests for reprints should be sent to: David E. Meycr. Human Performance Center, Department of Psychology. University of Michigan, 330 Packard Rd.. Ann Arbor, Mich. 48104. P. C. Gordon is now at the Department of Psychology and Social Relations, Harvard University. Cambridge. Mass. 0138. units and even smaller subunits (Lashley, 1951). At the top of the hierarchy, there are conceptual-dependency networks (Schank. 1972), surface-structure sequences of words (Chomsky, 1965), and phonemic clauses (syntagma) composed of rhythmic syllable groups (Boomer \& Laver, 1968; Kozhevnikov \& Chistovich, 1965). During production, a speaker presumably converts these compounds into smaller units such as individual syllables (Liberman, 1970: MacKay, 1972, 1974), phonemes (Fromkin, 1973a; Shattuck-Hufnagel \& Klatt, 1979), allophones (Liberman, 1970; Tatham, 1970; Wickelgren, 1969), and phonetic features (Chomsky \& Halle, 1968; Jakobson, Fant, \& Halle, 1951). In turn, these units may be realized as spatial articulatory targets (Henke, 1966; MacNeilage, 1970; Mermelstein, 1973), motor commands (Fromkin, 1966; Liberman, Cooper, Shankweiler, \& Studdert-Kennedy, 1967), and acoustic templates (Ladefoged, DeClerk, Lindau, \& Papcun, 1972; Lindblom, Lubker, \& Gay, 1979). Various mechanisms could mediate 
the conversion of linguistic information from one level to the next. It has been proposed that production processes rely on temporary storage buffers, memory-scanning routines, spreading activation, and output monitors of one kind or another (Baars, Motley, \& MacKay, 1975; Dell \& Reich, 1980; Henke, 1966; MacKay, 1970, 1982; Shaffer, 1976; Shattuck-Hufnagel. 1979; Sternberg, Monsell, Knoll, \& Wright. 1978).

The present article concerns the role of phonetic features in articulatory motor programming. Phonetic features include ones such as the place, voicing, and manner of articulation of consonant phonemes (Ladefoged, 1975). For example, consonants like $/ \mathrm{m} /, / \mathrm{s} /$, and $/ \mathrm{k} /$ have labial, alveolar, and velar places of articulation. respectively. One of them, $/ \mathrm{m} /$, is voiced, and the other two, $/ \mathrm{s} /$ and $/ \mathrm{k} /$, are voiceless. Their manners of articulation also differ, being respectively nasal, fricative, and stop.

We focus on the programming of phonetic features for several reasons. Feature analyses of speech segments have occupied a significant place in formal linguistic theory (Jakobson et al.. 1951). Phonetic features might constitute an important interface between intermediate linguistic units (viz., words, syllables, and phonemes) and physical subunits (viz., articulatory targets and motor commands) of speech. However, the status of these fea-

\footnotetext{
'We use the term "phonetic feature" in the same sense as a number of previous investigators (e.g. Fromkirı, 1971, pp. 223-227; Miller \& Eimas, 19761. This term refers to sets of correlated articulatory and acoustic factors that together distinguish allophones of one phonemic class (e.g., /b/) from allophones of another phonemic class (e.g., $/ \mathrm{p} /$ ). With respect to the voicing feature, for example, the relevant factors include voice-onset time, extent of first-formant transitions, magnitude of aspiration, and so forth, which characterize voiced and voiceless consonants in initial syllable position (Stevens \& Klatt, 1974: Lisker \& Abramson. 1964). Al a more general level, our experiments might also be said to involve variations of "phonological features," which provide more abstract distinctions between phonemic classes (Chomsky \& Halle, 1968; Mackay. 1978).
}

tures as part of the production process remains controversial. Some psycholinguists have offered what they consider to be good evidence of the role played by independently coded features (Bradshaw, 1970: Fromkin, 1971; 1973a, 1973b; Kent \& Minifie, 1977; MacKay, 1978), but others have questioned whether sufficient data exist to justify including them as part of performance models (e.g., Shattuck-Hufnagel. 1979: Shattuck-Hufnagel \& Klatt. 1979). Resolving this controversy could help to clarify a significant aspect of speech production.

In subsequent sections, we first review some representative evidence regarding the units of speech production. Then we outline a response-priming procedure that we have adopted to study the motor programming of phonetic features. Three experiments with this procedure are reported. The results concern the latency and accuracy of simple utterances involving placeof-articulation and voicing features of stop consonants. Our goal is to show that these features indeed play a salient role in motorprogramming operations. We also intend to determine more about how the output of various features is controlled. It will be demonstrated that a type of interactive-activation model, similar to ones proposed for word recognition, speech perceplion, and typing (EIman \& McClelland, 1984: McClelland \& Rumelhart, 1981; Rumelhart \& Norman, 1982), may account nicely for some of the obtained data. This demonstration helps strengthen the connections among theoretical descriptions of various input and output processes related to cognition.

\section{EVIDENCE FOR UNITS OF Speech Production}

The justification for postulating certain units of speech production rests heavily on three types of data. First, there is speech rate, the amount of speech produced per unit of time (Bradshaw, 1970: Lackner \& Levine, 1975: Landauer, 1962: Mackay, 
1974; Sternberg et al., 1978). Second, there is coarticulation, a temporal overlapping of the movements used to produce neighboring linguistic units (Fowler, 1980; Kent, 1976a; Kent \& Minifie, 1977; Moll \& Daniloff, 1971). Third, there are speech errors, systematic exchanges, substitutions, or deletions of elements in an utterance (Fromkin, 1971, 1973a, 1973b; Garrett. 1975, 1980: MacKay, 1970, 1972: ShattuckHufnagel. 1979). All of these data bear at least indirectly on the status of phonetic features in speech production, but they have significant limitations.

\section{Speech Rate}

Some studies of speech rate have been conducted to examine how the relationship between phonetic features of successive segments in an utterance affects the utterance's total duration. Bradshaw (1970) asked subjects to pronounce alternating syllables like "vah, mah, vah, mah," and "vah, nah, vah, nah." The rate of production for the former type of phrase was slower than for the latter type. This may be attributed to the fact that the phonemes $/ \mathrm{V} /$ and $/ \mathrm{m} /$ have similar places of articulation, one being bilabial (articulated by the two lips) and the other labiodental (articulated by the upper lip and lower front teeth). In contrast. the phonemes $/ \mathrm{v} /$ and $/ \mathrm{n} /$ have different places of articulation, the latter being alveolar (articulated by the tongue tip and front roof of the mouth) rather than labiodental.

It has been claimed that variations of speech rate depend on the underlying phonetic features of an utterance, as well as on the structural properties of linguistic units like syllables, words, and phrases (Bradshaw, 1970; Lackner \& Levine, 1975; MacKay, 1974; Sternberg et al., 1978). However, rate effects could stem at least parlly from peripheral interactions between the articulators during the physical output of speech. They do not necessarily reflect the properties of central mechanisms that prepare motor programs before an utter- ance starts. As a result, data involving speech rate leave unanswered questions about what, if any, role is played by phonetic features in programming operations.

\section{Coarticulation}

Further evidence regarding the status of phonetic features in speech production comes from studies of anticipatory coarticulation. The data show that phonetic features of speech segments downstream in an utterance are sometimes articulated ahead of other features associated with segments upstream. For example, anticipatory coarticulation has been observed in utterances such as "free Ontario," where lowering of the velum for the nasal consonant $/ n /$ takes place during articulation of the earlier vowel /i/ (Moll \& Daniloff, 1971). This indicates that phonetic features like nasality and vowel quality may be output as independent units during execution of an articulatory motor program.

Still, care must be taken in generalizing from coarticulation phenomena. Many phonemes have features (e.g., place of articulation) whose alternative values, unlike nasality, are incompatible with those of other speech segments. Because of their incompatibility, these features will not necessarily exhibit coarticulation. even though they function as separate underlying speech units. This may increase the difficulty of identifying the important features and of discovering how they are utilized. As Kent and Minifie (1977) noted, no systematic criteria exist for determining the compatibility of various features and segments. Consequently, feature-based descriptions of coarticulation are relatively ad hoc.

It should also be noted that some coarticulation of phonetic features perhaps stems from mechanical interactions between articulators, just as variations of speech rate do (Kent \& Minifie, 1977). After an utterance has started and speech rate or coarticulation can be observed physically, a speaker may have already finished most of the interesting mental activ- 
ities in production. Coarticulation does not necessarily reflect the properties of motorprogramming operations per se. The possible confounding of peripheral and central factors in coarticulation has led some investigators to examine other types of production data, such as speech errors.

\section{Speech Errors}

Speech errors have attracted considerable attention because they can reveal details about mental activities that organize and plan an utterance before overt speech begins (Garrett, 1975, 1980). When an error occurs in which an early part of the intended utterance is replaced by a later part, this implies that the two parts must have coexisted logether at some time before the error. The amount of speech spanned by an exchange or substitution of elements gives an indication of how far ahead speech is planned. The types of elements that participate in these errors also suggest what units are being manipulated during production processes.

Based on an extensive corpus of speech errors collected under natural conditions, Fromkin (1971) claimed that phonetic features play a significant role in the planning stages of speech production. She cited instances such as a person saying "glear plue sky" when the intended utterance was "clear blue sky." In this case, it appears that the voicing features from the phonemes $/ \mathrm{k} /$ and $/ \mathrm{b} /$ have been exchanged to yield the phonemes $/ g /$ and $/ \mathrm{p} /$. However, Shattuck-Hufnagel and Klatt (1979) argued that feature-exchange errors are very rare and might be explained as minor artifacts.

In addition, there are other reasons to question the interpretation of error data. Speech errors recorded under natural conditions can be contaminated by a listener's differential biases toward detecting some types of errors as opposed to others (Mackay. 1970). The detectibility of speech errors depends on the acoustic characteristics of an utterance and on a listener's perceptual set (Bond \& Garnes. 1980: Cole
\& Jakimik, 1980). Collections of errors are not entirely random samples. Thus, arguments based on the frequency of particular error types must be treated with caution. For individual phonetic features, it seems likely that their participation in speech errors could be underestimated by comparison with errors involving larger, more salient, units.

One way to deal with these latter problems would be to induce speech errors under carefully controlled experimental conditions. Indeed, a few investigators have started to take this kind of approach (e.g., Baars et al., 1975: Dell, 1984: Mackay, 1978). An alternative solution would be to seek other complementary measures of speech performance.

\section{AN APPROACH BASED ON SPEECH LATENCY}

The preceding considerations have led us to assess the role of phonetic features in speech production by measuring speech latency, the reaction time to begin an utterance upon command. Latency data are attractive because they overcome some of the difficulties associated with interpreting speech errors, rate, and coarticulation (Sternberg et al., 1978). Speech latency can be measured under conditions in which errors occur very infrequently. The measurements do not depend on a listener's perceptual biases, whereas these biases may influence what speech errors are recorded. Even sma!l latency differences, on the order of 10 milliseconds or less, are highly reliable and have potentially significant theoretical implications. It is possible to control effects on latency caused by ancillary mechanical aspects of articulation. especially if the initial physical movements for an utterance are held constant across experimental conditions. Thus, the latency differences should mainly reflect the mental activities underlying speech production. unlike coarticulation and the rate of continuous speech. which may confound central and peripheral articulatory factors. 


\section{The Response-Priming Procedure}

To measure speech latency, we have adopted a response-priming procedure. The procedure incorporates a series of discrete test trials, as Figure 1 illustrates. On each trial, a primary and secondary vocal response are first specified for a subject, who must prepare to produce the primary response as quickly and accurately as possible. After the preparation interval, there are warning signals followed by either a primary-response signal (a high-pitch tone) or a secondary-response signal (a low-pitch tone). When the primary-response signal occurs, the subject has to produce the prepared primary response immediately. When the secondary-response signal occurs instead, the subject is supposed to switch and quickly produce the secondary response rather than the primary response. The latency and accuracy of the primary and secondary responses are measured as a function of linguistic relationships between the two response types. As discussed more fully later, we take various steps to control, monitor, and evaluate the nature of subjects" preparation for the primary response. This allows the contributions of mental and physical preparatory activities to be treated separately. Our goal is to examine the role of central programming operations without confounding peripheral factors.

The rationale of the response-priming procedure parallels those of priming procedures developed in other areas of cognitive psychology (e.g.. Meyer \& Schvaneveldt, 1976; Meyer, Yantis. Osman, \& Smith,

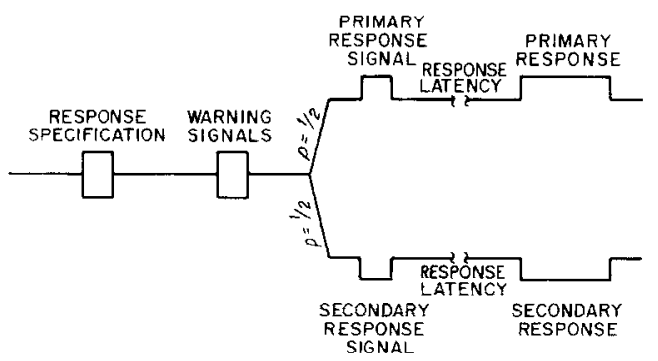

FIG. 1. Outline of the response-priming procedure used to measure speech latencies in Experiments 1 through 3 .
1984; Posner \& Snyder, 1975). Assuming that a subject highly prepares to produce the primary response, we analyze the latencies of secondary responses to make inferences about the nature of articulatory motor programming and execution. The time taken to switch and produce a secondary response instead of the primary response should reflect how programming opcrations work. depending on the relationship between the two responses. Thus, by observing variations in the secondary-response latency, it may be possible to get a better picture of which linguistic units contribute to speech production.

Several investigators have already used versions of the response-priming procedure to study arm movements (Rosenbaum. 1980), finger movements (Rosenbaum \& Kornblum, 1982), and speech production (Meyer, Sternberg, Knoll, \& Wright, 1978). Results of these studies generally support the procedure's rationale. In particular, Meyer et al. (1978) asked subjects to produce primary and secondary vocal responses consisting of short word sequences. The secondary responses (e.g. "dog cup") were reversals of the primary responses (e.g., "cup dog"). Some of the responses consisted of semantically unrelated words, as in the preceding example, while others consisted of semantically related words (e.g. "cat dog" and "dog cat"). There was a significant interaction between response type and semantic relatedness. Primary-response latencies did not differ as a function of relatedness, indicating that subjects can highly prepare their primary responses before the latency interval starts, and that these responses do not depend subsequently on factors like long-term memory structure. Secondaryresponse latencies increased as the words? relatedness decreased. The latency difference indicates that a switch to produce the secondary response requires a significant amount of additional programming. and that memory structure influences the necessary programming operations. Given this 
and other past successes of the responsepriming procedure, we are hopeful that the procedure might provide more information about the role of phonetic features in speech production.

\section{Overview of Present Experiments}

For each experiment reported here, vowel-consonant (VC) syllables were used in constructing the primary and/or secondary responses. We selected VC syllables because they constitute minimal amounts of speech that can be both produced and perceived naturally (Liberman et al., 1967). This allows us to manipulate the phonetic features of the primary and secondary responses in a relatively simple context. The VC syllables seemed appropriate because it is possible to keep their initial vowels constant as the features of the terminal consonants vary. Such constancy helps reduce variations in peripheral articulatory adjustments that a subject makes as part of preparing to produce different syllables (Sternberg et al., 1978). As a result, interpretation of the speech latencies is less problematic: observed latency effects may be attributed more readily to the properties of central-programming operations.

We did not use CV syllables, which also constitute minimal amounts of natural speech (cf. MacKay, 1972). Latency data would be harder to interpret for them, given that subjects can easily adjust the starting positions of their articulators to produce initial consonants, depending on what phonetic features are present. For example, anticipatory movements of the lips before the phonemes $/ \mathrm{p} /$ and $/ \mathrm{b} /$ could contaminate the latencies associated with producing the syllables "puh" and "buh."

While each experiment included a sample of VC syllables, some important details of the response-priming procedure differed from one experiment to the next. Both the primary and secondary responses in Experiment 1 consisted of VC syllable pairs. For reasons to be discussed later, the primary and secondary responses in Experi- ments 2 and 3 each consisted of single VC syllables rather than syllable pairs. Furthermore, Experiment 3 also included consonant-vowel-consonant (CVC) syllables as primary responses.

\section{EXPERIMENT 1}

During Experiment 1, the primary responses were utterances of two concatenated syllables, $V C_{1}$ and $V C_{2}$, spoken in rapid succession. The secondary responses were utterances of these same syllables ordered as $V C_{2} V C_{1}$, reversing the primary response. We chose the vowel $/ \Lambda$ and the stop consonants $/ \mathrm{p} / . / \mathrm{b} /, / \mathrm{t} /$, and $/ \mathrm{d} /$ to create the syllables for the responses. This yielded a syllable set whose members included "up," "ub," "ut," and "ud." The syllables were paired in all possible combinations, yielding a total of 12 primary and 12 secondary responses, as summarized in Table 1. The responses varied systematically in terms of the phonetic features shared by the stop consonants of the paired syllables. Some of the pairs had consonants with the same place of articulation (i.e., lat bial or alveolar), as in "up ub" and "ut ud." Others had consonants with the samo voicing (i.e., voiced or voiceless), as in "ub ud" and "up ut." For control purposes. there were also syllable pairs whose consonants had neither the same place of articulation nor the same voicing.?

Latencies of the primary and secondary responses were measured as a function of the relationship between the phonetic features of the consonants in the syllable pairs. We reasoned that if these features are important for articulatory motor programming, then response latencies ought to be affected by whether or not the syllables share some of the same features. For ex-

Alternatively, the syllable pairs could also be characterized in terms of how many different features they included. At present, our choice of focusing on the "same" rather than "different" features is somewhat arbitrary. However, it may be useful at some future point to determine whether "same" or "different" features are more important for performance in out lask. 
TABLE I

Pairs of VC Syllables Usfo to Designate Primaky anid St:conddary Rfsponses in Experiments 1 and 2

\begin{tabular}{|c|c|c|c|c|}
\hline Shared feature & & Syllable pair & & \\
\hline Voicing & up-ut & $u t-u p$ & $u b-u d$ & ud-uh \\
\hline Place & up-uh & $u b-u p$ & $u t-u d$ & $u d-u t$ \\
\hline None & up-ud & $u d-u p$ & $u t-u b$ & $u b-u t$ \\
\hline
\end{tabular}

ample, repeated use of identical parameter values by feature-programming operations could alter underlying activation levels that control their rate of progress, thereby influencing the time to complete necessary preparation activities (cf. MacKay, 1970). Analogous logic has been applied in studies of manual responses, where specifications of the response hand (right vs left) and finger (index vs middle) serve as programming parameters whose repeated use influences primary- and/or secondary-response latencies (Rosenbaum \& Kornblum. 1982).

More precisely, one might expect that a sharing of phonetic features between the syllables of the secondary responses would affect the secondary-response latencies. These responses should require a considerable amount of programming during the latency interval. because subjects are not supposed to prepare for them ahead of time. However, there need not be an effect of shared features on the primary-response latencies, assuming that programs for them are finished completely during the preparation interval before a response signal occurs. Observing the magnitudes and directions of the shared-feature effects on response latencies could therefore give us further information about the nature of programming operations and the contribution of phonetic features to speech production.

\section{Method}

Subjects. Nine University of Michigan undergraduates were sampled from the volunteer subject pool of the Human Performance Center. We screened these individuals in terms of two criteria: primary-response latency, and error rate. For inclusion in subsequent analyses, each in- dividual was required to have mean primary-response latencies less than 250 Inilliseconds and overall error rates less than $10 \%$. The latency criterion insured that the subjects were ones who prepared highly for the primary responses, a necessary prerequisite of the response-priming procedure. The error criterion insured that observed results came mainly from successful programming and execution, reducing contamination of the latency data by spurious malfunctions.

Based on these criteria, six of the nine initially sampled individuals were included as subjects. All of them spoke English as their native language. None reported any speech or hearing defects. They received wages of $\$ 3.00$ per session. In addition, we paid them bonuses that depended on the speed and accuracy of performance. The bonuses averaged about $\$ 1.50$ per session.

Apparatus. A Digital Equipment Corporation PDP 11/60 computer controlled the experiment. Visual messages, response syllables, and feedback appeared on the display screen of a Hewlett-Packard 2621A video terminal. Warning tones and response tones were played over Sennheiser HMD 224 headphones. A microphone attached to the headphones transmitted subjects" vocal responses to an A-to-D converter, which digitized the responses for on-line analysis by the computer. We measured response latencies with a software voicekey calibrated to compensate for lowlevel background noise in the audio equipment. The voicekey employed several statistical parameters derived from successive temporal windows of the speech waveform, including average power, frequency of zero crossings, etc. Its algorithms were similar 
to ones of other latency-measurement routines described in the literature (Rabiner \& Samber, 1975; Sherak, 1982; Sternberg et al., 1978). The voicekey monitored onsets of both voiced and voiceless speech segments with high sensitivity despite differences in spectral composition and energy. ${ }^{3}$

Design and procedure. Each subject participated for three sessions on separate days within a l-week span. A session lasted about 1 hour. There were seven trial blocks per session. The first session was used to instruct the subject and to provide practice. Data from it were not analyzed. The initial blocks of the second and third sessions served as warm-ups. Data from them were not analyzed either. The remaining test blocks of the second and third sessions yielded the results reported below.

The sequence of events during each trial was similar to the outline shown in Figure 1. First, the subject saw a pair of VC syllables presented side-hy-side in uppercase letters in the center of the display screen. The syllable pair designated both the primary and secondary responses. The primary response was supposed to be an utterance of the two syllables in the same order as their left-to-right spatial arrangement. The secondary response was supposed to be an utterance of the two syllables in reverse (right-to-left) order. We sampled the pairs from those listed in Table I. The syllables remained visible for 2 seconds while the subject prepared to produce the primary response. After the preparation interval, the syllables disappeared. and there was a 1 -second pause. Then the subject heard three $440-\mathrm{Hz}$ warning signals. Each warning signal lasted 100 milliseconds and

\footnotetext{
3 The interval between the first and second syllables of a response, and the overall response duration, were not measured as part of the present experiments. In future research, however, such measurements might provide useful supplementary data to interpret the effects of phonetic-feature relations on speech latency. For example, as Sternberg et al. (1978) have shown. measurements of an utterance s duration can reinforce inferences about articulatory motor programming and execution derived from latency measures.
}

was followed by a silent interval of 400 milliseconds. Following the last warning signal and silent interval, either a high-pitch $(660$ $\mathrm{Hz}$ ) primary-response signal or a low-pitch $(220 \mathrm{~Hz})$ secondary-response signal occurred. Each response signal had a probability of one-half. The high-pitch signal cued the subject to produce the primary response immediately, whereas the low-pitch signal cued the subject to produce the secondary response instead. We defined the response latency to be the amount of time from the onset of the response signal until the initial syllable of the subject's utterance triggered the software voicekey. Response accuracy was determined by the experimenter, who classified each syllable of the subject's utterance either as one of the members in Table 1 or as unintelligible. The experimenter made this classification without knowing what the correct response was. An error message appeared on the screen if the subject produced an incorrect response.

Events on a trial were arranged to increase the likelihood that the subject would highly prepare to produce the primary response. The regularity of the three warning signals permitted the onset of the primaryresponse signal to be anticipated precisely (Sternberg et al., 1978). Moreover, on 50\% of the trials, the subject did actually have to produce the primary response, making preparation for it worthwhile. During the initial instruction and practice session, it was strongly emphasized that each primary response should be produced as quickly as possible after the high-pitch response signal. The primary-response latencies were compared to a deadline derived by monitoring the subject's performance with a staircase tracking algorithm (Levitt. 1971). This deadline, which averaged about 220 milliseconds across subjects, fell roughly at the median of the primary-response latency distribution. Whenever a primary-response latency exceeded the deadline, the subject received a message that said "Response Too Slow." 
A trial block contained 24 trials; half required a primary response and half a secondary response. Each of the 12 syllable pairs in Table 1 occurred equally often as primary and secondary responses. The trial-by-trial order of the different syllable pairs and of the two alternative response signals was randomized within each block.

After each trial block, there was a 1 minute rest period, during which summary feedback was given about the mean latencies and error rates for the primary and secondary responses. Numerical values were entered on a score sheet so that each subject could see how his or her performance progressed. The experimenter also reminded the subject about the task instructions and encouraged good performance.

Each subject received bonus points based on response speed and accuracy. For every correct primary response whose latency fell below the specified deadline, 20 points were awarded. No points were awarded if a primary response exceeded the deadline, and 10 points were deducted for every incorrect primary response, regardless of its latency. Also, 1 point was deducted for every tenth of a second in the latency of a secondary response. If an incorrect secondary response occurred, an additional 20 points were deducted. Thus. while the point system emphasized very fast and accurate performance on the primary responses, it did not neglect reinforcement of secondary responses. Secondary responses were rewarded sufficiently to encourage rapid and accurate switching whenever the low-pitch response signal occurred instead of the high-pitch signal. A bonus of I cent was paid for each 10 points earned by a subject in his or her net point score.

Data analysis. We evaluated the data with a repeated-measures analysis of variance that included three factors: response type (primary versus secondary), shared phonetic features (voicing, place, or none), and subjects. Response type and shared features were treated as fixed factors, and subjects were treated as a random factor. In comparisons where the subject factor did not interact significantly with the other factors $(p>.25)$, within-cell estimates of error variance were pooled and used to test the reliability of main effects. This yielded more degrees of freedom for the meansquare error terms, increasing the power of the analysis (Winer, 1971). Latencies less than 100 milliseconds were classified as errors and not analyzed, because they involved premature activation of the voicekey. Also, latencies greater than 1200 milliseconds were not analyzed, because they resulted from failures to activate the voicekey. The excluded latencies constituted less than $1 \%$ of the data.

\section{Results}

The principal results are the mean latencies of correct primary and secondary responses, and the overall error rates for each response type. Table 2 summarizes them as a function of the relationship between the phonetic features of the two syllables that composed each response. We report the effects of shared features on the mean latencies by giving latency differences plus-orminus one standard error.

Response latencies. The latencies of correct primary responses averaged 230 milliseconds. They tended to be longer when the terminal consonants of the syllable pairs had some shared phonetic features than when there were no shared features. However, the effects of the shared features did not reach a statistically significant level. Primary responses with a shared voicing feature were $5 \pm 5$ milliseconds slower than primary responses with neither a shared voicing nor a shared place-of-articulation feature $[F(1,762)<1.0 ; p>.25]$. Primary responses with a shared place-ofarticulation feature were $6 \pm 5$ milliseconds slower than primary responses with no shared features $[F(1.762)=1.27 ; p>.25]$.

The latencies of correct secondary responses averaged 460 milliseconds. $230 \pm$ 25 milliseconds greater than the primary- 
TABLE 2

MEAN LATENCIES AND ERROR RATES FROM EXPERIMENT 1

\begin{tabular}{ccccc}
\hline & \multicolumn{2}{c}{ Primary response } & \multicolumn{2}{c}{ Secondary response } \\
\cline { 2 - 4 } Shared feature & $\begin{array}{c}\text { Latency } \\
(\mathrm{msec})\end{array}$ & $\begin{array}{c}\text { Error } \\
(\mathrm{r})\end{array}$ & $\begin{array}{c}\text { I atency } \\
(\mathrm{msec})\end{array}$ & $\begin{array}{c}\text { F.rror } \\
(\mathrm{r})\end{array}$ \\
\hline Voicing & 231 & 12.0 & 470 & 11.1 \\
Place & 232 & 8.5 & 459 & 5.7 \\
None & 226 & 6.6 & 453 & 6.3 \\
\hline
\end{tabular}

response latencies $[F(1,5)=85.4 ; p<.01]$. There was a significant effect of one shared phonetic feature on the secondary-response latencies. When the secondary responses contained two syllables that had the same voicing, their mean latency was $17 \pm 8$ milliseconds longer than the mean latency for secondary responses with no shared features $[F(1,768)=4.28 ; p<.05]$. A shared place-of-articulation feature also increased the secondary-response latencies, but not significantly. Secondary responses whose two syllables had the same place of articulation took $6 \pm 8$ milliseconds longer than those with no shared features $\mid F(1,768)<$ $1.0 ; p>.25] .^{1}$

We also analyzed the response latencies for the individual pairs of syllables. The effect of shared voicing on secondary responses was approximately the same regardless of whether the syllables contained voiced or voiceless consonants. Syllable pairs with two voiceless consonants took about 18 milliseconds longer on the average to produce than did pairs with one voiced and one voiceless consonant, and pairs with two voiced consonants took about 16 milliseconds longer. Likewise the effect of shared place of articulation on secondary

\footnotetext{
+ It is also possible to compare the mean latency of secondary responses that had a shared voicing feature versus those that had a shared place feature. The latency difference for them was $11 \pm 8$ milliseconds $[F(1.768=1.38 . p>.10]$. Although this difference was not reliable, there are other reasons to conclude that a shared place feature caused less effect than a shared voicing feature did in Experiment 1. For example, an examination of the accompanying error rates (Table 2) supports the latter conclusion
}

responses was approximately the same regardless of whether the syllable pairs contained labial or alveolar consonants. Syllable pairs with two labial consonants took about 8 milliseconds longer on the average than did pairs with one labial and one alveolar consonant, and pairs with two alveolar consonants took about 4 milliseconds longer.

Error rates. The pattern of errors for primary and secondary responses complements the latency data. Subjects made crrors on approximately $9 \%$ of the primary responses and $8 \%$ of the secondary responses. Significantly more errors $111.5 \%$ vs $6.4 \%$ ) occurred for both primary and secondary responses whose syllables had the same voicing feature than for those without any shared features $[F(1,1148)=$ $13.7 ; p<.01]$. A shared place-of-articulation feature did not affect the error rates significantly $[\mathrm{F}(1,1148)<1.0 ; \mathrm{p}>.25]$. The error rates and mean latencies tended to correlate positively within the primary $\mathrm{re}-$ sponses and within the secondary responses. There is no evidence that the shared-feature effects on the latency data resulted from speed-accuracy trade-offs of the type occasionally encountered in reaction-time research (Pachella, 1974).

In addition, we looked more closely at the nature of the specific errors produced on each individual syllable of the primary and secondary responses. About $68 \%$ of the errors involved changing the voicing feature but not the place of articulation of a consonant. For example, when they were incorrectly produced, the consonants $/ \mathrm{p} /$ and $/ \mathrm{t} /$ often tended to be output as $/ \mathrm{b} /$ and $/ \mathrm{d} /$. 
respectively. Among the remaining errors, about $28 \%$ involved changing the place of articulation but not the voicing feature of a consonant. For example, the consonants $/ \mathrm{p} /$ and $/ \mathrm{b} /$ were sometimes produced as $/ \mathrm{t} /$ and $/ \mathrm{d} /$, respectively. Only about $4 \%$ of the errors consisted of changes in both the place of articulation and voicing features of a consonant (e.g., producing /d/ instead of $/ \mathrm{p} /$ ). This error pattern was very similar for the first and second syllables of a pair. It did not vary greatly as a function of the response type (primary vs secondary) or the number of features shared between the consonants of the syllables. The fact that most errors stemmed from changes of single features is consistent with previous analyses of naturalistic slips of the tongue (Fromkin, 1971), and it may have further theoretical significance, as we outline later. 5

\section{Discussion}

The results of Experiment 1 take a step toward clarifying the role of phonetic features in speech production, and they raise interesting questions for further investigation. Beforehand, it might have been predicted that features shared between the syllables of an utterance should reduce the latencies of primary and/or secondary responses. This seems reasonable on the assumption that less time would be needed to program and output speech segments when some of the same component operations are used repeatedly. In other situations, repetition of component operations often speeds performance (Kornblum, 1973). Yet we found no such latency reduction. Instead, the shared features either increased response latencies or had no effect.

\footnotetext{
Following our previous discussion, however, it should be remembered that these error rates may depend partly on the experimenter's perceptual biases. and not entirely on subjects' production processes. Thus, the present pattern of errors should be interpreted cautiously, just as we advised for naturalistic slips of the tongue (cf. Fromkin. 1971)
}

The absence of any significant sharedfeature effects on the latencies of primary responses presumably happened because subjects prepared those responses highly before the latency interval started. Our results regarding the primary-response latencies do not imply that phonetic features play little role in programming operations. If motor programs for the primary responses are compiled completely in advance, then contributions of shared features to them would not appear during subsequent latency measurements. As previous investigators have noted (Klapp, Abbott, Coffman, Greim, Snider, \& Young, 1979), linguistic factors generally have less impact on latencies (simple reaction times) of highly prepared utterances than on latencies (choice reaction times) of unprepared utterances (cf. Sternberg et al., 1978).

By contrast, the latencies of secondary responses presumably depended on the nature of operations that occurred during the motor programming and/or execution of those responses. Our response-priming procedure was designed specifically to require additional processing during the latency interval whenever subjects produced a secondary instead of primary response. The procedure apparently achieved this aim, since secondary-response latencies were considerably longer than primary-response latencies.

In particular, a voicing feature shared by the two syllables of a secondary response may have slowed the progress of programming operations. Latencies of secondary responses were significantly longer when the syllable pairs had a shared voicing feature than when they had neither shared voicing nor shared place of articulation. Although the magnitude of the voicing effect (17 milliseconds) was not extremely large. it was reliable and comparable in magnitude to important latency differences reported by previous investigators of speech phenomena. For example, the effect of a single shared voicing feature in Experiment 1 exceeds another interesting effect reported by 
Sternberg et al. (1978), who found that appending an additional item to a short word list yielded approximately a 10-millisecond increase in the latency to start pronouncing the list rapidly. The present shared-voicing effect allows further detailed models of articulatory motor programming to be formulated, as we outline later (General Discussion).

On the other hand, the status of shared place-of-articulation features in speech production remains uncertain at this point. Such features slowed both primary and secondary responses slightly, but their latency effects were relatively unreliable. This might mean that place of articulation, unlike voicing, does not function as an independent parameter in the programming of speech segments. However, we are reluctant to accept the latter conclusion without further efforts. Perhaps Experiment 1 was not powerful enough to detect real underlying effects associated with the programming of commands for a segment s place of articulation. To be specific, suppose that programs to produce the two syllables of a primary response were stored as separate routines in a motor-program buffer. Then subjects could have sometimes produced their secondary responses simply by rearranging the order of the syllable routines, without recompiling them from scratch (Meyer et al.. 1978). This might attenuate any apparent inhibitory effects caused by shared place-of-articulation features."

\section{EXPERIMENT ?}

The purpose of Experiment 2 was to assess more fully the role of phonetic features in speech production and to increase the sensitivity of the response-priming proce-

\footnotetext{
"Of course, subjects did not always simply rearrange the syllable routines of the primary response to produce the secondary response. If they had, then the shared voicing features would have caused no effects on secondary responses. The presence of a sharedvoicing effect precludes a strong form of the rearrangement hypothesis and implies that the motor program for a primary response is fairly rigid.
}

dure. It replicates and extends the effects of shared voicing and place of articulation on latency measurements. As before, we used VC syllables with terminal stop consonants (Table 1), but rather than including two concatenated syllables of this type. each primary and secondary response consisted of a single syllable. The secondary response could not be produced simply by reordering the components of the primary response. Subjects were instructed to prepare highly for the primary response and to disregard the secondary response unless a secondary-response signal actually occurred. Thus, the format of Experiment 2 more strongly encouraged the compilation of new programs for the secondary responses during the measured latency interval.

\section{Method}

Subjects. A new group of six individuals, selected from the same population as in Experiment I, served as paid subjects. Each subject satisfied the criteria of having sufficiently short (equal or less than 250 milliseconds) primary-response latencies and low (equal or less than $10 \%$ ) error rates.

Apparatus, design, and procedure. The apparatus, design, and procedure were similar to those of Experiment 1. except for the modifications outlined above. Each subject participated individually during one practice session and two test sessions on separate days. The sessions were divided into discrete trial blocks. On each trial, the subject was presented visually with one of the syllable pairs from Table 1. The fïrst syllable of the pair designated the primary response, and the second syllable designated the secondary response. Thus, the terminal consonants of the two responses shared either the same place of articulation. the same voicing, or no place and voicing features. There was a 2 -second interval that allowed the subject to prepare for producing the primary response. After the preparation interval, the response syllables disappeared, and three warning signals oc- 
curred in sequence, followed by a primaryor secondary-response signal. Response latency and accuracy were measured as a function of the phonetic-feature relations between the alternative responses.

\section{Results}

Again the principal results are the mean latencies of correct primary and secondary responses, and the overall error rates for each type of response. Table 3 shows these as a function of the relations between the phonetic features of the syllable pairs.

Response latencies. Correct primary responses had latencies that averaged 185 milliseconds overall. The relationship between the phonetic features of the primaryand secondary-response syllables did not affect the primary-response latencies significantly. A shared voicing feature reduced the latencies of primary responses by $4 \pm 4$ milliseconds $[F(1,819)<1.0 ; p>$ $.25]$, and a shared place-of-articulation feature reduced them by $0 \pm 4$ milliseconds $\mid F(1.819)<1.0 ; p>.25]$.

Correct secondary responses had latencies that averaged 435 milliseconds overall. They exceeded the mean primary-response latencies by $250 \pm 29$ milliseconds $[I(1,5)$ $=74.3: p<.01]$. Furthermore, shared phonetic features significantly affected the secondary-response latencies even though they did not affect the primary-response latencies. The secondary-response latencies were $23 \pm 8$ milliseconds longer when they involved the same voicing feature as the prepared primary response than when they involved no shared features $[F(1.780)=$ $8.98 ; p<.011$. The secondary-response la- tencies were $16 \pm 6$ milliseconds longer when they involved the same place of articulation as the prepared primary response than when they involved no shared features $[F(1,780)=4.11 ; p<.05]$. There was an insignificant difference of $7 \pm 10$ milliseconds between the effects of the shared place and shared voicing features $[F(1,780)$ $<1.0 ; p>.25]$.

Subsequent analyses of latencies for individual responses indicated that the effects of shared features were reasonably consistent across the various syllable pairs, just as in Experiment 1. Secondary responses from pairs that had two voiceless consonants took about 26 milliseconds longer on the average than did those from pairs that had one voiceless and one voiced consonant. The analogous effect on secondary responses from pairs that had two voiced consonants was about 22 milliseconds. Likewise, the effect caused by shared places of articulation on secondary responses was approximately the same regardless of whether the consonants were labial or alveolar. Secondary responses from syllable pairs that had two labial or two alveolar consonants took about 17 and $15 \mathrm{mil}$ liseconds longer than did those from pairs that had one labial and alveolar consonant.

Error rates. The error rates tended to be positively correlated with the response latencies. However, they were very low $(3.4 \%)$ and did not differ significantly as a function of the phonetic-feature relations between the paired syllables used for the primary and secondary responses $(p>.10$ in all cases). Among mistakes that occurred on individual syllables, the pattern was sim-

TABLE 3

Mtan Latencies and ERror Ratis from Experiment 2

\begin{tabular}{ccccc} 
& \multicolumn{2}{c}{ Primary response } & \multicolumn{2}{c}{ Secondary response } \\
\cline { 2 - 5 } Shared feature & $\begin{array}{c}\text { Latency } \\
(\mathrm{msec})\end{array}$ & $\begin{array}{c}\text { Error } \\
(\%)\end{array}$ & $\begin{array}{c}\text { Latency } \\
(\mathrm{msec})\end{array}$ & $\begin{array}{c}\text { Error } \\
(\%)\end{array}$ \\
\hline Voicing & 182 & 1.2 & 445 & 5.1 \\
Place & 186 & 3.5 & 438 & 4.7 \\
None & 186 & 2.0 & 422 & 3.9 \\
\hline
\end{tabular}


ilar to what emerged during Experiment 1. A majority of the errors involved spuriously changing just a single feature; changes of both voicing and place of articulation were very rare (less than $10 \%$ ).

\section{Discussion}

The results of Experiment 2 strengthen those of Experiment 1. As before, we found no significant effects of shared phonetic features on the latencies of primary responses. This supports our assumption that subjects highly prepare those responses before the latency interval. Still, shared voicing increased the latencies of secondary responses. A place of articulation shared by the primary and secondary response syllables also increased the secondary-response latencies significantly. The observed effects were somewhat larger than in Experiment 1, suggesting that our modification of the response-priming procedure increased its sensitivity as intended. We therefore have more confidence that shared phonetic features may slow programming operations when a subject switches from a state of high preparation for one utterance to produce another utterance instead.

\section{EXPERIMENT 3}

The purpose of Experiment 3 was to examine how other structural aspects of the response syllables affect the magnitudes of response latencies and the impact of shared phonetic features. We again used VC syllables for the secondary responses, but the primary responses were CVC syllables. In particular, the phoneme $/ \mathrm{s} /$ was appended to the first syllables of pairs in
Table 1, yielding a set of $\mathrm{CVC}_{1}-\mathrm{VC}_{2}$ syllable pairs as shown in Table 4 , where the terminal stop consonants of the pairs again share various combinations of phonetic features. Our use of the CVC syllables, that is, "sup," "sub," "sut," and "sud," for the primary responses allowed us to address several issues arising from the results of Experiments 1 and 2.

First, the CVC syllables provided an additional control on subjects' physical articulatory adjustments for the primary responses (cf. Experiment 1). Regardless of what phonetic-feature relations existed between the terminal consonants of the $\mathrm{CVC}_{1}-\mathrm{VC}_{2}$ syllable pairs, subjects had to adopt about the same vocal-tract configuration to produce the initial/s/ in the primary responses. This further ensured that any effects of those relations on the secondary-response latencies were due to central programming operations and not peripheral factors. Second, the CVC syllables let us examine what happens when the terminal consonants of the primary and secondary responses are identical. In Experiments 1 and 2 , it would not have been meaningful for subjects to perform with $V C_{1}-V_{2}$ syllable pairs whose terminal consonants were identical. because it would have been theoretically and empirically difficult or impossible to distinguish production of the primary and secondary responses. However, in Experiment 3, the two types of response were always distinguishable by the presence or absence of an initial /s/ as part of the utterance. Consequently, we can look at whether an identity between the $\mathrm{VC}$ components of the primary and secondary responses affects their laten-

TABLE 4

Pairs of CVC-VC Syliables Whusf Members Were Primary and Stconijary Responses in Experimian 3

\begin{tabular}{|c|c|c|c|c|}
\hline \multirow{2}{*}{$\begin{array}{c}\text { Shared feature } \\
\text { Voicing and place }\end{array}$} & \multicolumn{4}{|c|}{ Syllable pair } \\
\hline & sup-up & $s u b-u b$ & $s u t-u t$ & $s u d-u d$ \\
\hline Voicing & sup-ut & sut-up & sub-ud & sud-ub \\
\hline Place & sup-ub & sub-up & sut-ud & sud-ut \\
\hline None & sup-ud & iud-up & $s u t-u b$ & sub-ut \\
\hline
\end{tabular}


cies. This provides further insights about the motor programming of shared phonetic features.

Third, as a corollary of the preceding point, the CVC syllables may reveal more about whether the initial and terminal consonants of a syllable are programmed as separate units. If there is such independence, then the results of Experiment 3 should be similar to those of Experiment 2 . Adding an extra segment, that is, the phoneme $/ s /$, to the start of primary responses would not eliminate the effects on secondary responses caused by phonetic features shared between the terminal consonants of the two response types. In contrast. if syllables are programmed holistically, then Experiment 3 could yield results qualitatively different from those of the first two experiments; for example, the phonetic-feature effects might disappear completely.

\section{Mcthod}

Subjects. Four new individuals participated as paid subjects. Each subject satisfied the latency and accuracy selection criteria.

Apparatus, design, and procedure. The apparatus. design, and procedure were similar to those of Experiment 2. except for the modification just outlined in the structure of the primary responses. During a given trial block, each syllable pair from Table 4 was presented visually on two trials. The first member of a pair designated the primary response, and the second member designated the secondary response. Re- sponse latencies and accuracy were measured as a function of the phonetic-feature relations between the terminal consonants of the primary $(\mathrm{CVC})$ response syllables and the secondary ( $\mathrm{VC}$ ) response syllables.

\section{Results}

The principal results are shown in Table 5 , which presents mean latencies of correct responses and overall error rates.

Response latencies. Correct primary responses had latencies that averaged 178 milliseconds overall. The phonetic-feature relations between the terminal consonants of the primary-and secondary-response syllables did not affect the primary-response latencies significantly. Primary responses with a shared voicing feature were $2 \pm 6$ milliseconds slower than ones without any shared features $[F(1,581)<$ $1.0 ; p>.25]$. Primary responses with a shared place-of-articulation feature were 5 \pm 6 milliseconds slower than ones without any shared features $|F(1.581)<1.0 ; p\rangle$ .25]. Even an exact identity between the terminal consonants of the primary and secondary responses had no significant effect on the primary-response latencies. Primary responses with both shared voicing and shared place-of-articulation features were 1 \pm 6 milliseconds faster than ones without any shared features $[F(1.581)<1.0$ : $p>.251$.

Correct secondary responses had latencies that averaged 478 milliseconds overall. They were $300 \pm 18$ milliseconds slower than the latencies of correct primary responses $[F(1.3)=277.8: p<.01]$. Shared

TABLE 5

MHAN LATHNCIES AND ERROR RATES HROM EXPERIMENT 3

\begin{tabular}{lcccc} 
& \multicolumn{2}{c}{ Primary response } & \multicolumn{2}{c}{ Secondary response } \\
\cline { 2 - 5 } Shared teature & $\begin{array}{c}\text { Latency } \\
(\mathrm{msec})\end{array}$ & $\begin{array}{c}\text { Error } \\
(\%)\end{array}$ & $\begin{array}{c}\text { Latency } \\
(\mathrm{msec})\end{array}$ & $\begin{array}{c}\text { Error } \\
(\%)\end{array}$ \\
\hline Voicing and plice & 175 & 3.1 & 461 & 0.6 \\
Voicing & 178 & 7.5 & 491 & 5.6 \\
Place & 181 & 6.3 & 476 & 5.6 \\
None & 176 & 3.8 & 2.5
\end{tabular}


phonetic features significantly affected the latencies of correct secondary responses. The latencies of secondary responses were $15 \pm 7$ milliseconds longer when they shared one phonetic feature with the primary response than when they shared no features $[F(1,547)=3.86 ; p<.05]$. These phonetic-feature effects were equally large regardless of whether they involved shared voicing or place of articulation. The pattern of latencies across individual syllables was similar to what occurred in Experiment 2. On the other hand, an exact identity between the terminal consonants of the primary- and secondary-response syllables decreased the secondary-response latencies significantly. Secondary responses were 15 \pm 7 milliseconds faster when the terminal consonants of the paired response syllables had both the same voicing and the same place of articulation than when their terminal consonants differed completely $[F(1.547)=3.85 ; p<.05]$. This decrease occurred despite the latency increase caused by a single shared feature.

Error rates. There were $4.4 \%$ errors overall. For primary responses and for secondary responses considered separately, the error rates correlated positively with the mean latencies. Significantly more errors occurred when the responses had either shared voicing or shared place of articulation than when they had no shared features $[F(1,638)=4.81, p<.05$; and $F(1,638)=3.26, .05<p<.10]$. Responses with both shared voicing and shared place of articulation yiclded somewhat fewer errors than did those without any shared features, but the latter difference was not reliable $[F(1,638)\langle 1.0 ; p\rangle$ .25]. Again the errors on individual syllables tended to involve changing just a single feature (cf. Experiments 1 and 2, Results).

\section{Discussion}

The results of Experiment 3 replicate and extend those of Experiments 1 and 2. We continued to find increases of secondaryresponse latencies when the paired response syllables had different terminal con- sonants with shared features. The effects caused by shared voicing and by shared place of articulation were equally large and reliable. This supports our inference that shared features milay slow the programming operations needed to switch from a prepared primary response to another secondary response. Adding an extra phoneme, $/ \mathrm{s} /$, to the start of the primaryresponse syllables did not alter the shared-feature effects. Thus, we also infer that subroutines for initial consonants of syllables may be programmed separately from those for terminal consonants.

In this context, it is noteworthy that an exact identity between the terminal consonants of the paired syllables actually speeded secondary responses rather than slowing them down. The pattern of results suggests that subjects may "strip off" the subroutine for an initial consonant $(C)$ of at primary-response CVC syllable and use the remaining (VC) subroutines for an otherwise equivalent secondary response. without completely reprogramming their utterance. Such stripping is consistent with a theory proposed by MacKay (1972, 1974) about syllable structure. According to him, CVC syllables contain an initial consonant group and a terminal vowel group with a vowel-consonant combination (cf. Kent. 1976b; Kozhevnikov \& Chistovich, 1965). He supported this theory by citing evidence from speech errors, where exchanges of phonemes often involve the initial consonants of neighboring syllables. An independence of subroutines for the initial conso nant group and terminal vowel group of a primary syllable would make it easier to use the vowel group for other purposes, just at we found.

As mentioned previously (Experiment 1. Discussion), however, one should not conclude that the components of a motor program for an utterance are completely flexible. Subjects cannot, or at least do not, typically rearrange the routines associated with different syllables of a bisyllabic tillerance to produce another utterance that has a reversed syllable order (footnote 6). Per. 
haps motor programs are rigid with respect to the relative order but not to the absolute serial positions of their components, so that subroutine "rearrangement" but not "stripping" is a difficult or impossible operation.

It is also instructive in other respects to compare the results for secondary responses that shared both voicing and place features with the primary responses (Table 5, top row) versus those that had only one shared feature (Table 5, middle rows). Since a combination of two shared features yielded relatively short latencies, whereas single shared features yielded relatively long latencies, we may treat the responses with no shared features (Table 5 , bottom row) as constituting a type of "neutral" condition. Latencies greater than those obtained in the neutral condition could reflect inhibitory effects, and lesser latencies could reflect facilitative effects, allowing us to separately assess the "costs" and the "benefits" of shared phonetic features (Posner \& Snyder, 1975). We will pursue this analysis further as part of the General Discussion.

\section{General Discussion}

Two results from the three experiments are most intriguing. One is the inhibitory effect of shared phonetic features on secondary-response latencies. The other is a lack of any shared-feature effects on primary-response latencies. The overall pattern is summarized in Table 6, which shows the feature effects for primary and secondary responses averaged across Experiments 2 and 3 , our most comparable studies.

\section{Peripheral versus Central Preparation}

It seems doubtful that the inhibitory effects of shared phonetic features on secondary-response latencies stem merely from physical adjustments of the articulators (e.g., lips, tongue, and larynx) made to prepare for the primary responses. The experiments performed here all constrained subjects initial state of peripheral preparation by using primary syllables with con-
TABLE 6

Mean Effects of Shared Phonetic Features on Primary- and Secondary-Response Latencies AVERAGED ACROSS EXPERIMENTS 2 AND 3

\begin{tabular}{ccc}
\hline & \multicolumn{2}{c}{$\begin{array}{c}\text { Shared-feature } \\
\text { effect }(\mathrm{msec})\end{array}$} \\
\cline { 2 - 3 } Response type & Voicing & Place \\
\hline Primary & 0 & -2 \\
Secondary & -19 & -16 \\
\hline
\end{tabular}

Note. Each entry was calculated by subtracting the mean latencies of responses that had either shared voicing or shared place of articulation from the mean latency of responses without any shared features. Negative entries indicate inhibitory effects of the shared features.

stant initial segments, that is, the vowel $/ \Lambda$ / for Experiments 1 and 2 and the consonant /s/ for Experiment 3. To the extent that variations in peripheral preparation might occur across the different types of response-syllable pairs (Tables 1 and 4), they should cause the shared phonetic features to facilitate subjects' utterances of secondary responses, not inhibit them. For example, adjusting the tongue mechanically to speed production of the phoneme $/ t$ for the primary response "ut" would likewise put subjects in a better position to produce the phoneme $/ d$ / of the secondary response "ud," which has the same place of articulation. However, we observed no such facilitation; a shared place feature increased secondary-response latencies rather than decreasing them. This leads us to reject an explanation of our results in terms of a peripheral-preparation hypothesis. ${ }^{?}$

The latencies of primary responses are also rele. vant to testing for the presence of peripheral preparatory adjustments. Suppose that subjects did not just prepare to produce the primary-response syllable at the start of each trial, but also made some physical adjustments of their articulators in anticipation of the secondary-response syllable. Then this would presumably affect the primary-response latencies as well as the secondary-response latencies. depending on what phonetic features (e.g.. place of articulation) are shared by the two response types. However. we found no significant effects of phonetic-feature relations on the latencies of primary responses (Table 6). Such a result reinforces our conclusion that peripheral preparation contributed little to the observed pattern of latency data. 
Instead, we infer that phonetic features play a significant role in central preparation and articulatory motor programming. These features may provide an essential bridge between intermediate-level phonemic units and lower-level motor commands. Their role is most salient when programming operations occur during the measured latency interval, as happens with secondary responses under our responsepriming procedure. The outcome of the present experiments goes against claims made by some observers who have denied the importance of phonetic features for speech production (Shattuck-Hufnagel \& Klatt, 1979).

\section{Interactive-Activation Model}

Figure 2 shows a theoretical framework that might help to explain the effects of shared phonetic features in more detail. Following the terminology of McClelland and Rumelhart (1981), we call this framework an "interactive-activation model." Here speech production relies on an interconnected network of phoneme nodes, phonetic-feature nodes, and articulatorycontrol mechanisms (cf. MacKay, 1982). The phoneme nodes have excitatory links with the feature nodes, and in turn, the feature nodes have excitatory links with the articulatory-control mechanisms. Moreover, pairs of phoneme nodes that share identical features are connected to each other by a set of lateral inhibitory links. Such an arrangement is structurally similar

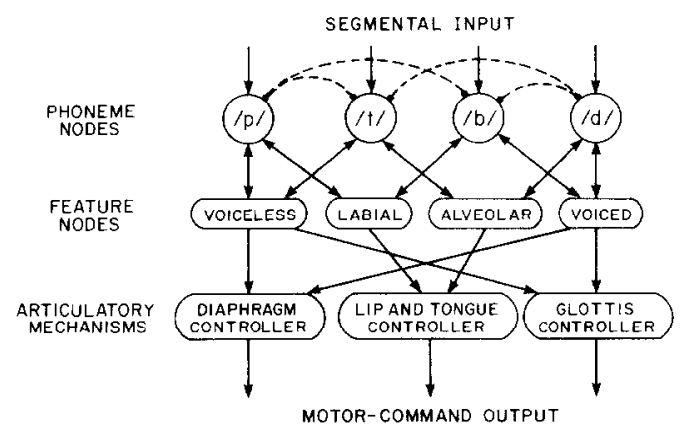

FIG. 2. An interactive-activation model for producing speech segments. in some respects to ones proposed by MacKay (1970, 1971) and Dell (1984) for speech production, and by Rumelhart and Norman (1982) for typing. It also resembles some models of speech perception and word recognition (Elman \& McClelland. 1984: McClelland \& Rumelhart, 1981).

We assume that when programming operations prepare to produce a particular segment (e.g., the phoneme $/ \mathrm{p} /$ ), an activation signal is transmitted in a top-down fashion to the appropriate phoneme node. which then activates its associated phonetic features and articulatory-control mechanisms (e.g.. the labial and voiceless nodes). As part of the process, residual activation may also pass back upward from the feature nodes to other phoneme nodes in a bottomup fashion, partially activating them. Provision for an upward as well as downward flow of activation is included so that the network can handle performance in a variety of tasks besides speech production, for example, short-term memory and speech perception, where articulatory mechanisms may be used (Hintzman. 1967: Liberman et al., 1967; Wickelgren, 1966). The purpose of the lateral inhibitory links is to keep the residual activation below threshold at those nodes whose phonemes are not part of current stimuli or responses. This helps to prevent intrusions of spurious segments during input and output. As in certain sensory systems (Ratliff, 1961), the lateral inhibition serves an important tuning function here.

The interactive-activation model accounts qualitatively for most of the results from Experiments 1 through 3. If the model is correct, then preparing to produce a designated primary VC or CVC syllable should inhibit the nodes of phonemes contained in other secondary VC syllables whose terminal consonants have some but not all of the same features as the primary syllable. To overcome the inhibition subsequently, more activation of the inhibited phoneme nodes must accrue before they pass sufficiently strong signals down through the net. 
work. The result would be an increase of the secondary-response latencies, which is what we found (Experiments 2 and 3). On the other hand, preparing to produce a designated primary CVC syllable should activate the nodes of phonemes associated with a secondary VC syllable whose vowel and terminal consonant are identical to those of the primary syllable. Consequently, the secondary-response latencies would be reduced in the latter case, just as we found (Experiment 3). This account extends naturally to handle the production of bisyllabic primary and secondary responses as well (Experiment 1).

\section{Relation to Other Empirical Phenomena}

The results of Experiments 1 through 3 and the interactive-activation model may be related to a variety of other empirical phenomena obtained in research on speech production, perception, and manual performance.

Tongue twisters, speech errors, and aphasia. As mentioned earlier, Bradshaw (1970) reported that subjects' rate of production was slower for extended utterances like "thah, nah, thah, nah," than for ones like "vah, nah, vah, nah." He attributed the observed difference to the fact that the former utterance contains initial consonants with similar places of articulation whereas the latter does not. In effect, a shared place-of-articulation feature appears to induce disruptive tongue twisting. This phenomenon occurs likewise for betterknown utterances such as the infamous phrases "Peggy Babcock Peggy Babcock Peggy Babcock" (Butterworth \& Whittaker, 1980) and "unique New York unique New York unique New York" (Schoroup, 1973). which involve repetitions of similar place features that cause speech hesitations and errors. While the rate reduction and slips of the tongue associated with alternation between similar places of articulation could be due at least partly to peripheral aspects of production, for example. muscular fatigue, some of the difficulty might arise instead from lateral inhibitory links among phoneme nodes.

Similarly, the interactive-activation model could explain patterns of speech errors that occur in ordinary discourse and in utterances produced by certain types of aphasics. Investigators have found that exchanges and substitutions of phonemes under natural conditions tend to be most prevalent when the phonemes share phonetic features (Fromkin, 1971; MacKay, 1970: Shattuck-Hufnagel \& Klatt. 1979). For example, analyses of confusion matrices reveal more slips of the tongue involving the pairs of phonemes $/ p /-/ /$ and $/ \mathrm{p} /-/ \mathrm{b} /$ than involving $/ \mathrm{p} /-/ \mathrm{d} /$. Broca's aphasics exhibit the same sorts of confusion (Blumstein, 1973; Trost \& Canter, 1974). These normal and pathological errors might stem from inhibitory links not suppressing residual activation enough at the level of adjacent phoneme nodes (cf. MacKay, 1970, 1971).9

Manual performance. Principles of the interactive-activation model also apply to other domains of motor control, not just speech production. Using a responsepriming procedure related to ours, Rosenbaum and Kornblum (1982) studied the performance of subjects who operated keys by pressing the index and middle fingers of their right and left hands. On each trial, there was a primary response (e.g. . a left index-finger keypress) and an alternative

\footnotetext{
${ }^{*}$ The attribution of tongue-twisting phenomena to
} central. not just peripheral, factors is supported by studies of subvocal (covert) speech production, which suggest that tongue twistcrs may cause crrors even when uttered implicitly (Dell, 1974). It should also be noted that such errors may depend both on shared phonetic features and on complex sequential alternation of similar or identical phonemes, as in "unique New York" (Schoroup. 1973).

"Moreover. there was evidence in our data that shared phonetic features increase the probability of speech errors. This might be attributed to a tendency toward producing unsuccessfully inhibited segments. just as in the case of naturalistic slips of the tongue. Such a failure could likewise account for why most of the present errors involved changing just a single phonetic feature. 
secondary response (e.g., a right middlefinger keypress). Latencies of primary and secondary responses were measured as a function of what dimensions they had in common. The relevant dimensions included hand (right vs left) and finger (index vs middle) position. Paralleling our results, secondary responses with dimensions common to the primary response had longer latencies than did those without any shared dimensions. In particular, secondary responses by fingers on the same hand as would have been used to make the primary response were about 30 milliseconds slower on the average than other secondary responses. Inhibitory effects of shared hand or finger positions did not occur in the case of primary responses. Kornblum (1965) also found a comparable pattern of effects, using a sequential choice-reaction procedure.

These results suggest that keypresses and manual features (i.e., hand and finger position) may be represented by higherlevel and lower-level nodes in a control network analogous to the arrangement of phoneme and phonetic-feature nodes of Figure 2. Given this representation, preparing to produce a keypress with a finger on the right (or left) hand might inhibit keypresses by other fingers on the same hand. The inhibition could arise through a set of lateral links between adjacent keypress nodes, just as it does for phoneme nodes with shared phonetic features.

Speech perception. Finally, the interactive-activation model is relevant to some aspects of speech perception. In experiments described elsewhere (Gordon \& Meyer, 1984; Meyer \& Gordon, 1983, 1984; Meyer, Gordon, \& Benson, in preparation), we have discovered strong connections between the perception and production of phonemes with shared phonetic features. Some of these experiments incorporated a modification of the response-priming procedure used here. Subjects had to prepare for articulating a designated primary-response syllable. Following the preparation interval, either a high-pitch response signal or an auditory stimulus syllable was presented. The high-pitch signal cued the subjects to produce the primary response immediately. When the auditory stimulus syllable occurred instead of the response signal, no primary response was required. Instead, the subjects pressed one of several alternative finger keys to indicate what consonant they heard in the stimulus syllable. Their latencies depended systematically on the relationship between the phonetic features of the stimulus syllable and the previously prepared response syllable. In particular, the keypresses took longer if the two syllables contained different consonants that had the same voicing feature (Meyer \& Gordon, 1983).

The observed inhibitory effect on speech perception is analogous to ones revealed by the present experiments. In each case, preparing to produce an utterance vocally slowed the subsequent processing of other phonemes that had some of the same features as the prepared utterance. Our results, together with those of other investigators (e.g.. Cooper, 1974: Cooper \& Nager, 1975), suggest a close correspondence between the phoneme nodes, phonetic-feature nodes, and/or lower-level mechanisms used to perceive and produce speech. This is consistent with various theories in which perceptual-motor links have been proposed between speech production and perception (Fant, 1967: Ladefoged et al. 1972; Liberman et al., 1967; Lindblom et al., 1979).

\section{Future Research}

Beside being relevant to extant data on speech production and perception, the interactive-activation model also suggests some interesting directions for future research. Our formulation of the model assumes that activation from higher-level units of speech (e.g., syllables) flows to a set of phoneme nodes, which in turn activate lower-level phonetic-feature nodes and articulatory-control mechanisms. This formulation glosses over certain complexities of serial order and allophonic variation. In 
particular, it ignores the fact that the physical realization of stop consonants such as $/ \mathrm{p} /, / \mathrm{b} /, / \mathrm{t} /$, and $/ \mathrm{d} /$ depends on their serial position within a syllable (Ladefoged, 1975). The articulatory and acoustic correlates of voicing, for example, differ as a function of whether a consonant is initial. medial. or terminal. Additional constraints therefore need to be built into the model to accommodate such differences. It might be appropriate to replace the "phoneme nodes" of Figure 2 with segment nodes marked for serial order, making them more closely resemble "context-sensitive" allophones (Dell, 1984; Wickelgren, 1969). It might also be appropriate to differentiate the phonetic-feature nodes further, acknowledging that the correlates of features such as voicing and place of articulation depend on serial order and other contextual factors (cf. footnote 1 ).

Further empirical research should guide these refinements. To be specific, one could examine subjects' performance in producing primary and secondary vocal responses that consist of CVC syllables. If the current version of the model (Figure 2) is correct, then subjects ought to have greater difficulty producing syllables like "bad" and "pat" as opposed to "pad" and "bat." This is because the former syllables, but not the latter, have initial and terminal stop consonants with a shared voicing feature and are consequently more susceptible to effects of lateral inhibition. Under a model that has position-specific segment and feature nodes, however, such inhibition need not necessarily occur across serial positions. Thus, if no latency differences were to emerge during production of the various CVC syllables, then the extended version of the model would gain support over the original version. Likewise, it would be worthwhile to collect more data regarding the production of consonant clusters (e.g.. pt/. $/ \mathrm{mp} /$, and $/ \mathrm{sp} /$ ) and to elaborate the model based on them. ${ }^{10}$

"We thank D. G. Mackay for bringing these points more fully to our attention.

\section{ConClusion}

The response-priming procedure provides a valuable tool for supplementing previous data on speech production. It is sufficiently sensitive and flexible to reveal fine details of how elementary linguistic units are programmed centrally before articulation begins peripherally. There seem to be significant excitatory and inhibitory interactions between the mechanisms that control the top-down and bottom-up flow of information regarding phonemes and phonetic features. These interactions would not necessarily be as apparent from other phenomena like spcech crrors, ratc, or coarticulation. With further refinement, perhaps the response-priming procedure will tell us even more about the programming of phonetic features and other important linguistic units.

\section{REFERENCES}

BAAKS, B. J., MUILEY, M. T., \& MACKAY, D. G. (1975). Output editing for lexical status in artificially elicited slips of the tongue. Journal of Vorbal Leaming and Verbal Bchavior, 14, 382391.

Bu.umstein, S. E. (1973). A phonological investigation of aphasic speech. The Hague: Mouton.

BONd, Z. S., \& Garnes, S. (1980). Misperceptions of fluent speech. In R. A. Cole (Ed.), Perception and production of fluent spech. Hillsdale, N.J.: Erlbaum.

Boomer, D. S.. \& LAver, J. D. (1968). Slips of the tongue. British Journal of Disorders of Communication, 3, 2-12.

Bradshaw, J. L. (1970). Phonetic homogeneity and articulatory lengthening. British Jolmal of Psychology, 61, 499-507.

Butterworth, B., \& Whittaker. S. (1980). Peggy Babcock`s relatives. In G. E. Stelmach \& J. Requin (Eds.), Tutorials in moror bohavior. Amsterdam: Ellsevier/North-Holland.

Chomsky, N. (1965). Aspects of the theory of synax. Cambridge, Mass.: MIT Press.

CHOMSKY, N., \& HALLE, M. (1968). The sound pattern of English. New York: Harper \& Row.

Col.K. R. A. \& IAKIMIK, I. (1980). A model of speech production. In R. A. Cole (Ed.). Perception and production of fluent specch. Hillsdale, N.J.: Erlbaum.

CoOper, W. E. (1974). Perceptuomotor adaptation to a speech feature. Perception \& Psychophysics. $16,229-234$.

CoOper, W. E.. \& Nagir, R. M. (1975). Perceptual- 
motor adaptation to speech: An analysis of bisyllabic utterances and a neural model. Journal of the Acoustical Society of America, 58, 256-265.

DeLL, G. S. (1974). Tongue twisters. Unpublished master's thesis, University of Toronto.

DELL. G. S. (1984). The representation of serial order in speech: Evidence from the repeated phoneme effect in speech errors. Journal of Experimental Psychology: Leaming. Memory, and Cognition, 10, 222-233.

Dell, G. S., \& Reich, P. A. (1980). Toward a unified model of slips of the tongue. In V. A. Fromkin (Ed.), Errors in linguistic performance: Slips of the tongue, ear, pen, and hand. New York: Academic Press.

Elman, J., \& MCCl.el.l.and, J. L. (1984). Speech perception as a cognitive process: The interactiveactivation model. In N. Lass (Ed.). Speech and language (Vol. 10). New York: Academic Press.

FANT G. (1967). Auditory patterns of speech. In W. Wathen-Dunn (Ed.), Models for the perception of speech and visual form. Cambridge. Mass.: MIT Press.

Fowler, C. A. (1980). Coarticulation and theories of extrinsic timing. Journal of Phometics, 8, 113133.

Fromkin, V. A. (1966). Neuromuscular specification of linguistic units. Language and $S_{\text {peech }} \cdot \mathbf{9}, 170$ 199.

Fromkin, V. A. (1971). The non-anomolous nature of anomolous utterances. Langlat, Le $^{2}, 47,27-52$.

Fromkin, V. A. (1973a). Slips of the tongue. Scientific American, 229, 110-117.

Fromkin. V. A. (Ed.). (1973b). Spe'ech errors as linguistic e'vidence. The Hague: Mouton.

GARRETT, M. (1975). The analysis of speech production. In G. Bower (Ed.). Psychology of learning and motivation (Vol. 9). New York: Academic Press.

Garrett, M. (1980). Levels of processing in sentence production. In B. Butterworth (Ed.). Language production. London: Academic Press.

Gordon. P. C., \& Meyer, D. E. (1984). Perceptualmotor processing of phonetic features in speech. Journal of Experimental Psychology: Human Perception and Performance, 10, 153-178.

HENkt, W. L. (1966). Dynamic articulatory medel of speech production asing compater simulation. Unpublished doctoral dissertation. Massachusetts Institute of Technology.

HinTzMan, D. L. (1967). Articulatory coding in shortterm memory. Journal of Verbal Learning and Verbal Behavior, 6, 312-316.

JAKOBSON, R., FANT, C. G. M.. \& HALI.F, M. (1951). Preliminaries to speech analysis: The distinctive features and the ir correlates. Cambridge, Mass.: MIT Press.

KENT, R. D. (1976a). Models of speech production. In
N. J. Lass (Ed.), Contemporary issues in experimental phonetic's. New York: Academic Press.

KENT, R. D. (1976b). Syllabic complexity and syntagmatic rules for syllable production-A comment on "Aspects of the syntax of behavior" by D. G. MacKay. Quarterly Joumal of Experimental Psy chology, 28, 483-489.

KenT, R. D.. \& Minifie, F. D. (1977). Coarticulation in recent speech production models. Journal of Phonetics, 5, 115-133.

Kı АPP, S. T. (1974). Syllable-dependent pronunciation latencies in number naming: A replication. Journal of Experimental Psychology, 102, 1138 1140.

Ki.app. S. T., Abbott, J., Coffman, K., Grhim. D.. SNibFr, R., \& Younci. F. (1979). Simple and choice reaction time methods in the study of motor programming. Journal of Motor Beharior. $11,91-101$.

Kornblum. S. (1965). Response competition and/or inhibition in two-choice reaction time. Psychonomic Scichce, 2, 55-56.

Kornblum. S. (1973). Sequential effects in choice reaction time: A tutorial review. In $\mathrm{S}$. Kornblum (Ed.). Attention and performanc' $N$. New York: Academic Press.

KozheVvikov, V. A., \& Chistonich, L. A. (1965). Spech: Articulation and perception. Washington. D.C.: U.S. Govt. Printing Office.

L.ACKNeR. J. R., \& Levine, K. B. (1975). Speech production: Evidence for syntactically and phonologically determined units. Perception \& Psycherphysics, 17, 107-113.

LADEFOGED. P. 11975). A comrse in phonetics. New York: Harcourt Brace Jovanovich.

LAderOGED, P., DLCl.ERK, J. I INDAL: M. \& PAPClN. G. (1972). An auditory-motor theory of speech production. U.C.L.A. Working Papere in Iing,uis. tics, $22,48-75$.

LANIDAUER, T. K. (1962). Rate of implicit speech. Perceptual and Motor Skills. 15, 646.

LASHI.FY, K. S. (1951). The problem of serial order in behavior. In L. A. Jeffress (Ed.). Cerebral mechanisms in behavior. New York: Wiley.

LEvitr, H. (1971). Transformed up-and-down methods in psychophysics. Joumal of the Acoustical Sorciety of America, 49, 467-477.

LiBERMAN, A. M. (1970). The grammars of language and speech. Cognitive Psychology, 1, 301-323.

Liberman, A. M., Cooper, F. S.. Shankweilik. D. P., \& Stliddert-Kennedi, M. (1967). Perception of the speech code. Psychological Rerien. $74,431-461$.

Lindblom, B. . LuhkER, J., \& GAY. T. (1979). Formant frequencies of some fixed-mandible vowels and a model of speech motor programming by predictive simulation. Journal of Plometics, 7, 147--161.

LISKER, I... \& ABRAMSON. A. S. (1964). A crom lan- 
guage study of voicing in initial stops: Acoustical measurements. Word, 20, 384-422.

MACKAY. D. G. (1969). Forward and backward masking in motor systems. Kybernetik, 2, 57-64.

MAKAY, D. G. (1970). Spoonerisms: The structure of errors in the serial order of speech. Neuropsichologia, 8, 323-350.

MAKKY, D. G. (1971). Stress pre-entry in motor systems. American Journal of Psychology, 84, $3.5-51$.

MACKAY, D. G. (1972). The structure of words and syllables: Evidence from errors in spcech. Cognitive Prychology, 3, 210-227.

MACKAY. D. G. (1974). Aspects of the syntax of behavior: Syllable structure and speech rate. Quarterly Journal of Experimental Psychology, 26. $642-657$

MA(KAY. D. G. (1978). Speech errors inside the syllable. In A. Bell \& J. B. Hooper (Eds.). Syllables and segments. Amsterdam: North-Holland.

M.KAY. D. G. (1982). The problems of flexibility, tluency, and speed-accuracy trade-off in skilled performance. Psychological Review, 89, 483-506.

Mac NeillagE. P. F. (1970). Motor control of serial ordering of speech. Psuchological Review', 77. 182196.

Mac Neilage. P., \& Laderoged. P. (1976). The production of speech and language. $\ln$ E. C. Carterette \& M. P. Friedman (Eds.). Handbook of perception (Vol. 7). New York: Academic Press.

MCClell.and, J, L... \& RlumelhakT, D. E. (1981). An interactive-activation model of context effects in lelter perception: Part 1 . An account of basic findings. Psychological Revie's'. 88, 375-407.

Mtrmelstian, P. (1973). Articulatory model for the study of speech production. Jomrnal of the Acolstical Societs of America, 53, 1070-1082.

Mryek, D. E.. \& Gordon. P. C. 1983, November). Shared mechanisms for perceiving and producing phonetic features in speech. Paper presented at the meeting of the Psychonomic Society, San Diego, Calif. Abstracted in Bulletin of the Psyihomemic Society, 22, 367.

Mi:yer, D. E., \& GoRdon. P. ('. (1984). Dependencies hetween rapid speech perception and production: Evidence for a shared sensory-motor voicing nutchanism. In H. Bouma \& D. G. Bouwhuis (Eds.). Attention and performance $X$. Hillsdale. N.J.: Erlbaum.

MeYEr, D. E.. GORdon. P. C.. \& Benson. P. Inhibilory effects of artic ulatory motor programming on seech perception: Consequences of a shared sensory-motor voiring mechanism. In preparation.

Mei ER, D. E., \& SChVanivei.jt. R. W. (1976). Meaning. memory structure. and mental processes. Science, (Washington, D.C.) 192, 27-33.

Meyer, D. E., Sternberg, S., Knoll, R. L., \& Wright. C. E. (1978, May). Memory retrieral and motor programming of related-word sequences. Paper presented at the meeting of the Midwestern Psychological Asociation, Chicago.

Meýer, D. E., Yantis, S., Osman. A. M., \& Smith. J. E. K. (1984). Discrete versus continuous models of response preparation: A reaction-time analysis. In S. Kornblum \& J. Requin (Eds.), Preparatory states and processes. Hillsdale, N.J.: Erlbaum.

Millek. J. L., \& Eimas. P. D. (1976). Studies on the selective tuning of feature detectors for speech. Jolernal of Phonetics, 4, 119-127.

MoLl, K. L., \& Daniloff, R. G. (1971). Investigation of the timing of velar movements during speech. Joumal of the Aconstical Society of America, 50 . $678-684$.

PACHEILA, R. G. (1974). The interpretation of reaction time in information processing research. In $\mathrm{B}$. H. Kantowitz (Ed.). Human information processing: Tutorials in performance' and cognition. Hillsdale. N.J.: Erlbaum.

Posner, M. I., \& SNyder, C. R. R. (1975). Facilitation and inhibition in the processing of signals. In P. M. A. Rabbitt \& S. Dornic (Eds.). Atlention and performance V. London/New York: Academic Press.

Rabinfer, L. R.. \& Samber, M. R. (1975). An algorithm for determining the endpoints of isolated utterances. Bell System Techical Joturnal, 54, $297-$ 315.

RATlifF, F. (1961). Inhibitory interaction and the detection and enhancement of contours. In W. A. Rosenblith (Ed.), Sensory communication. New York: Wiley.

Rosfnbalm, D. A. (1980). Human movement initiation: Specification of arm, direction, and extent. Jounal of Experimental Psychology: General. 109. 444-474.

Rosenbalim, D. A., \& Kornblem, S. (1982). A priming method for investigating the selection of motor responses. Acta Psychologia, 51, 223-243.

Rumelhart. D. E., \& Norman. D. A. (1982). Simulating a skilled typist: A study of skilled cognitivemotor pertormance. Cognitive Science, 6, 1-36.

ScholrtP, L. (1973). Unique New York unique New York unique New York. In Papers from the Ninth Regional Meeting, Chicago Linguistic Society.

SCHANk, R. (1972). Conceptual dependency: A theory of natural language understanding. Cognitive Prychology, 3, 552-631.

SHAFFER, L. H. (1976). Intention and performance. Psychological Review, 83, 375-393.

Shattick-Hlifnagel, S. (1979). Speech errors as evidence for a serial order mechanism in sentence production. In W. E. Cooper \& E. C. T. Walker (Eds.). Sentence processing: Psroholinguistic studies presented to Merrill Garrett. Hillsdale. N.J.: Erlbaum.

Shattuck-Hufnagei. S.. \& Klatt, D. H. (1979). 
The limited use of distinctive features and markedness in speech production: Evidence from speech error data. Journal of Verbal Learning and Verbal Behavior, 18, 41-55.

SHERAK, R. (1982). A real-time software voicekey and an application. Behavioral Research Methods and Instrumentation, 14, 124-127.

Sternberg, S., Monsell, S., Knoll, R. L., \& Wright, C. E. (1978). The latency and duration of rapid movement sequences: Comparisons of speech and typewriting. In G. Stelmach (Ed.), Information processing in motor control and learning. New York: Academic Press.

Stevens, K. N. \& KLATT, D. H. (1974). Role of formant transitions in the voiced-voiceless distinction for stops. Journal of the Acoustical Society of America, 55, 653-659.

Tatham, M. A. A. (1970). A speech production model for synthesis-by-rule. Working papers in Linguis- tics, (Vol. 6). Computer and Information Sciences Research Center, Ohio State University.

Trost, J. E., \& CANTER, G. J. (1974). Apraxia of speech in patients with Broca's aphasia: A study of phoneme production accuracy and error patterns. Brain and Language, 1, 63-79.

Wickelgren, W. A. (1966). Distinctive features and errors in short-term memory for English consonants. Journal of Verbal Learning and Verbal Behavior, 39, 388-398.

Wickelgren, W. A. (1969). Context-sensitive coding, associative memory, and serial order in (speech) behavior. Psychological Review', 76, 1-15.

WINER, B. J. (1971). Statistical principles in experimental design (2nd ed.). New York: McGrawHill.

(Received July 27, 1983)

(Revision received May 6, 1984) 